\title{
Erratum to: Ultrasonic and Eddy-Current Fatigue Monitoring of Austenitic Steel Welded Joints
}

\author{
A. V. Gonchar ${ }^{a, *}$, V. A. Klyushnikov ${ }^{a, * *}$, V. V. Mishakin ${ }^{a, * * *}$, and M. S. Anosov ${ }^{b, * * * *}$ \\ ${ }^{a}$ Mechanical Engineering Research Institute, Branch of Federal Research Center Institute of Applied Physics \\ of the Russian Academy of Sciences, Nizhny Novgorod, 603024 Russia \\ ${ }^{b}$ Nizhny Novgorod State Technical University Named after R.E. Alekseev, Nizhny Novgorod, 603950 Russia \\ *e-mail:avg-ndt@mail.ru \\ **e-mail: slavchuk2@yandex.ru \\ ***e-mail: imndt31@mts-nn.ru \\ ****e-mail: anosov-maksim@list.r
}

Received November 1, 2021; revised November 1, 2021; accepted November 1, 2021

DOI: $10.1134 / \mathrm{S} 1061830921090126$

The article "Ultrasonic and Eddy-Current Fatigue Monitoring of Austenitic Steel Welded Joints", written by A.V. Gonchar, V.A. Klyushnikov, V.V. Mishakin, and M.S. Anosov, was originally published electronically in Springer-Link on October 4, 2021 without Open Access. After publication in volume 57, issue 7, pages 570-578 the authors decided to make the article an Open Access publication. Therefore, the copyright of the article has been changed to (C) The Author(s) 2021 and the article is forthwith distributed under the terms of a Creative Commons Attribution 4.0 International License (http://creativecommons.org/licenses/by/4.0/, CC BY), which permits use, duplication, adaptation, distribution and reproduction of a work in any medium or format, as long as you cite the original author(s) and publication source, provide a link to the Creative Commons license, and indicate if changes were made.

The original article can be found online at https://doi.org/10.1134/S106183092107007X 